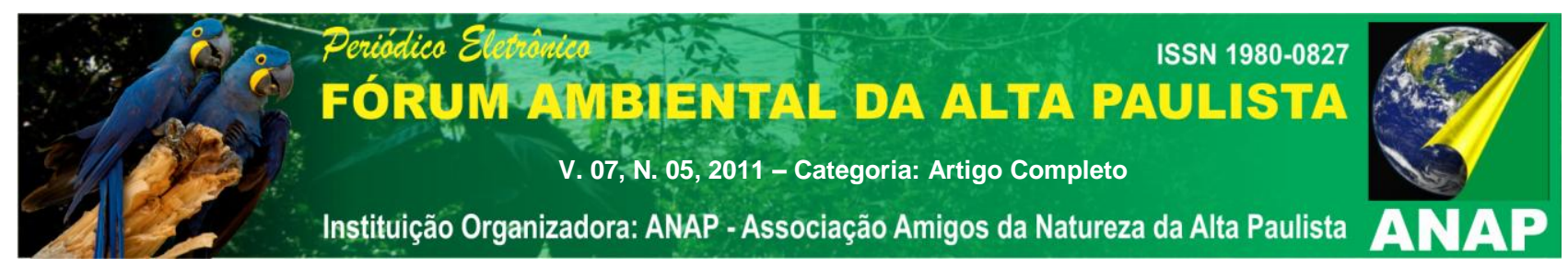

\title{
MEIO AMBIENTE E A IMPORTÂNCIA DOS PRINCIPÍOS AMBIENTAIS
}

\author{
Lucas Seolin Dias ${ }^{1}$ \\ Maurício Dias Marques ${ }^{2}$
}

RESUMO

Os princípios são a base, a proposição inicial, o alicerce, o fundamento, por isso a importância de princípios no que tange ao Meio Ambiente, ao Direito Ambiental. É a partir deles que se constroem as leis, regulamentos, normas, resoluções, de onde resultam ramificações, portanto extremamente importantes para configuração de um sistema bem elaborado. Esse conjunto de normas deve formar o sistema jurídico com finalidade de proteger, tutelar, resguardar todos os tipos de Meio Ambiente, seja ele Físico, Artificial ou Cultural. Dessa forma se buscará um maior desenvolvimento sustentável.

Palavras chave: princípios, meio ambiente, desenvolvimento sustentável.

\footnotetext{
${ }^{1}$ Bacharel em Direito, Faculdade de Direito da Alta Paulista (lucas_seolin@yahoo.com.br)

${ }^{2}$ Professor, Faculdade de Ciências Contábeis de Lucélia (mdmarques1985@gmail.com)
} 


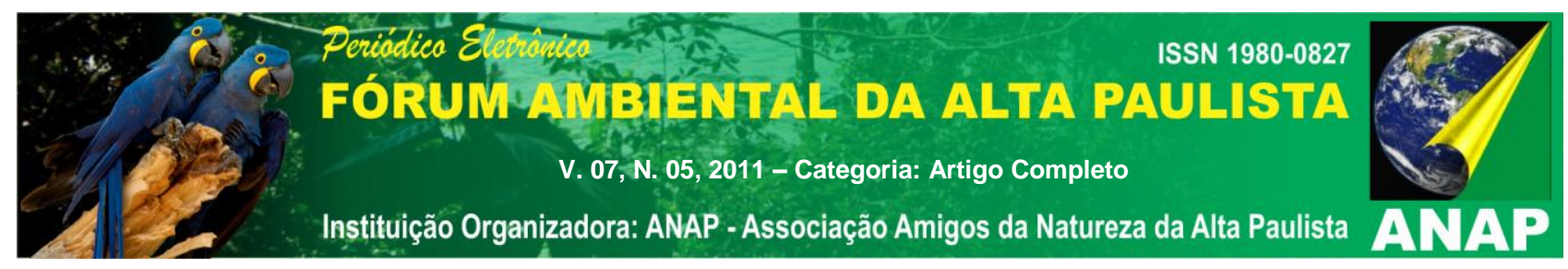

\section{INTRODUÇÃO}

Nos últimos anos, as discussões a respeito dos problemas ambientais ganharam destaque e a preocupação com o meio ambiente vem aumentando em devido à degradação da natureza e destruição dos recursos naturais, ações provocadas pelo homem. O presente artigo tem como objetivo trazer uma visão panorâmica do cenário ambiental em que vivemos e a importância dos princípios ambientais para a preservação e sustentabilidade do meio ambiente, tornando-o mais equilibrado.

\section{CONCEITO DE MEIO AMBIENTE}

O meio ambiente integra tanto a natureza original e artificial, quanto o solo, a água, o ar, a flora, o patrimônio histórico, paisagístico e turístico, ou seja, o meio físico, biológico, químico.

A Lei Federal o 6.938/81, que dispõe sobre a Política Nacional do Meio Ambiente em seu artigo $3^{\circ}$, inciso I, conceitua o meio ambiente como "um conjunto de condições, leis, influências e integrações de ordem física, química e biológica, que permite, obriga e rege a vida em todas as suas formas".

Ensina José Afonso da Silva (2000, p. 20) que:

O meio ambiente é, assim, a interação do conjunto de elementos naturais, artificiais e culturais que propiciem o desenvolvimento equilibrado da vida em todas as suas formas. A integração busca assumir uma concepção unitária do ambiente, compreensiva dos recursos naturais e culturais.

Segundo Celso Fiorillo (2008, p.20), a Constituição Federal de 1988 tutelou alguns tipos de meio ambiente, classificando em meio ambiente Natural, meio ambiente Artificial, meio ambiente Cultural e do Trabalho. Ademais nossa Constituição tratou de dois objetos de proteção ambiental: o meio ambiente em si, e a qualidade de vida.

O Meio Ambiente Natural é aquele que envolve aspectos físicos, como o solo, subsolo, os mares, rios, a fauna e flora, tutelado pelo artigo $225, \S 1^{\circ}$, I, III, VII. da CF: 


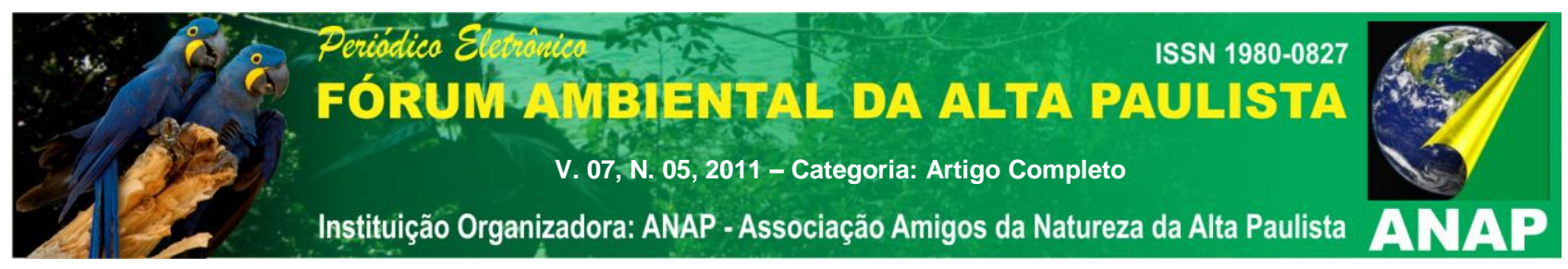

Art. 225. Todos têm direito ao meio ambiente ecologicamente equilibrado, bem de uso comum do povo e essencial à sadia qualidade de vida, impondo-se ao Poder Público e à coletividade o dever de defendê-lo e preservá- lo para as presentes e futuras gerações.

$\S 1$ - Para assegurar a efetividade desse direito, incumbe ao Poder Público:

1 - preservar e restaurar os processos ecológicos essenciais e prover o manejo ecológico das espécies e ecossistemas;

III - definir, em todas as unidades da Federação, espaços territoriais e seus componentes a serem especialmente protegidos, sendo a alteração e a supressão permitidas somente através de lei, vedada qualquer utilização que comprometa a integridade dos atributos que justifiquem sua proteção;

VII - proteger a fauna e a flora, vedadas, na forma da lei, as práticas que coloquem em risco sua função ecológica, provoquem a extinção de espécies ou submetam os animais a crueldade.

O Meio Ambiente Artificial são "as cidades", se refere aos espaços urbanos construídos, que é formado pelo conjunto de edificações e pelos equipamentos públicos. Segundo Celso Fiorillo (2002, p. 21):

O meio ambiente artificial recebe tratamento constitucional não apenas no art. 225, mas também nos arts. 182, ao iniciar o capítulo referente à política urbana; $21, X X$, que prevê a competência material da União Federal de instituir diretrizes para o desenvolvimento urbano, inclusive habitação, saneamento básico e transportes urbanos; $5^{\circ}, \mathrm{XXIII}$, entre alguns outros".

O Meio Ambiente Cultural se encontra conceituado no art. 216 da CF, como: "O bem que compõe o chamado patrimônio cultural traduz a história de um povo, a sua formação, cultura e, portanto, os próprios elementos identificadores de sua cidadania, que constitui princípio fundamental norteador da República Federativa do Brasil”.

E o Meio Ambiente do Trabalho é aquele em que as pessoas exercem suas atividades do dia-a-dia, suas atividades laborais.

Constitui meio ambiente do trabalho o local onde as pessoas desempenham suas atividades laborais relacionadas à saúde, sejam remuneradas ou não, cujo equilíbrio está baseado na salubridade do meio e na ausência de agentes que comprometam a incolumidade físico-psíquica dos trabalhadores, independente da condição que ostentem..." (FIORILLO, 2008, p. 22 ).

Edis Milaré (1992, p.8-9) também classifica o meio ambiente em:

(1)meio ambiente natural (constituído pelo solo, a água, o ar atmosférico, a flora, a fauna, enfim, a biosfera); (2) meio ambiente cultural (integrado pelo patrimônio 


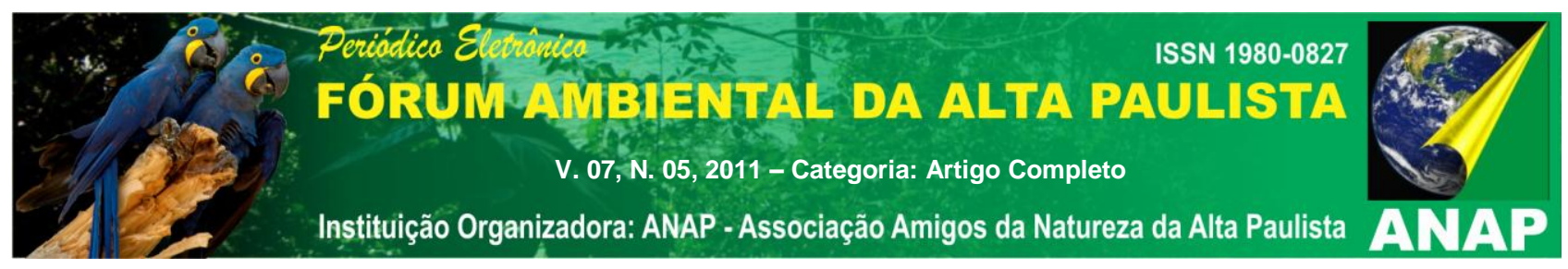

artístico, histórico, turístico, paisagístico, arqueológico, espeleológico); e (3) meio ambiente artificial (formado pelo espaço urbano construído, consubstanciado no conjunto de edificações, e pelos equipamentos públicos: ruas, praças, áreas verdes, enfim, todos os assentamentos de reflexos urbanísticos). Nem se há de excluir do seu âmbito o meio ambiente do trabalho dadas as inegáveis relações entre o local de trabalho e o meio externo. Anacefalia, leucopenia, saturnismo, asbestose e silicose são palavras que saíram dos compêndios médicos para invadir o cotidiano dos trabalhadores que mourejam em ambientes de trabalho hostis.

\title{
3. PRINCÍPIOS AMBIENTAIS FUNDAMENTAIS
}

Uma das novidades trazidas pela Constituição de 1988 foi um capítulo próprio relacionado ao Meio Ambiente, o que demonstra uma evolução importante para busca de um ambiente mais sustentável. Nosso ordenamento, doutrinadores do universo jurídico e estudiosos do meio ambiente trazem vários princípios importantes sobre o meio ambiente, entre eles:

3.1 Princípio do direito à sadia qualidade de vida: Não basta viver ou conservar a vida. É justo buscar e conseguir "qualidade de vida".

A Conferência das Nações Unidas sobre Meio Ambiente e Desenvolvimento, na Declaração Rio de Janeiro/92, afirmou que os seres humanos "tem direito a uma vida saudável".

\begin{abstract}
"A saúde dos seres humanos não existe somente numa contraposição a não ter doenças diagnosticadas no presente. Leva-se em conta o estado dos elementos da Natureza águas, solo, ar, flora, fauna e paisagem - para aquilatar se esses elementos estão em estado de sanidade e de seu uso advenham saúde ou doenças e incômodos para os seres humanos." (MACHADO, 2003, p. 48)
\end{abstract}

3.2Princípio do desenvolvimento sustentável: O uso dos recursos naturais deve ser racional, de forma a garanti-los às presentes e futuras gerações. Em resumo: desenvolver e conservar. 


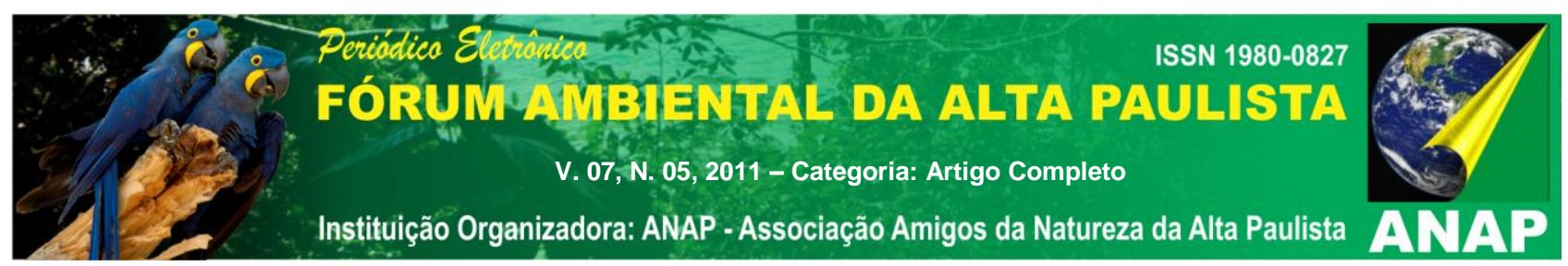

A CF consagra este princípio em dois momentos:

Art. 225 "todos têm direito ao meio ambiente ecologicamente equilibrado, bem de uso comum do povo e essencial à sadia qualidade de vida, impondo-se ao Poder Público e à coletividade o dever de defendê-lo e preservá-lo para as presentes e futuras gerações" (grifo nosso).

Art. 170 "a ordem econômica, fundada na valorização do trabalho humano e na livre iniciativa, tem por fim assegurar a todos existência digna, conforme os ditames da justiça social, observados os seguintes princípios: ...VI - defesa do meio ambiente".

Reforça este princípio o que se convencionou chamar de Princípio 3 da Declaração do Rio de Janeiro sobre Meio Ambiente e Desenvolvimento de 1992: "O direito ao Desenvolvimento deve ser exercido de modo a permitir que sejam atendidas equitativamente as necessidades de desenvolvimento e de meio ambiente das gerações presentes e futuras".

3.3 Princípio da prevenção e da precaução: "Medidas de precaução devem ser largamente aplicadas pelo estado, visando prevenir a degradação do meio ambiente"

É um principio fundamental que visa prevenir danos ao meio ambiente, pois o homem destrói com uma certa facilidade, porém para construir é bem mais difícil, mesmo para recuperar uma área degradada. Danificar uma área para depois restaurá-la em matéria ambiental é complicado, demora-se muito tempo, por isso surgiu este princípio.

A CF dispõe sobre o acautelamento (prevenção):

Art. 5, XXXV: "a lei não excluíra da apreciação do Poder Judiciário lesão ou ameaça a direito"

Art. 225: "... dever do Poder Público e da coletividade proteger e preservar o meio ambiente".

Art. 225, IV: "estudo prévio de impacto ambiental" 


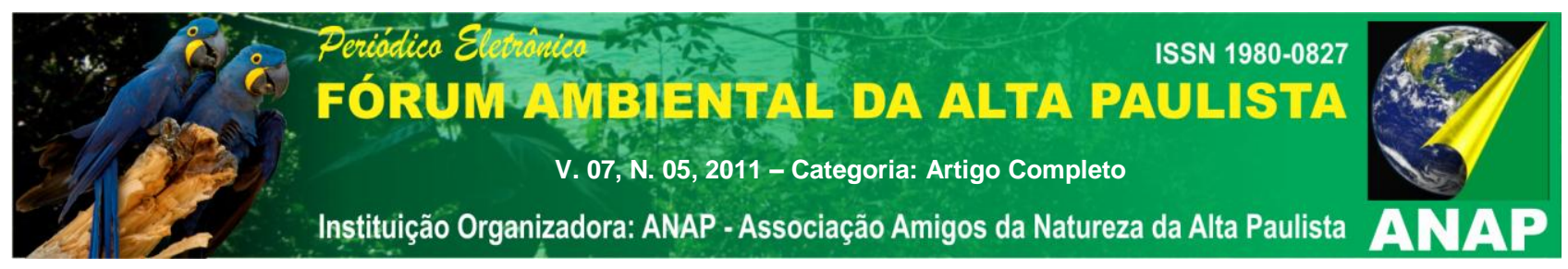

A Lei de Política Nacional do Meio Ambiente, Lei 6.938/81, nos arts. 9o e 10, fez constar instrumentos, como: o zoneamento ambiental, a avaliação de impacto ambiental e o licenciamento.

O Estatuto da Cidade, art. 2oㅡ., incisos IV, VI e XII: ordena o pleno desenvolvimento das funções sociais da cidade e da propriedade urbana, observadas as diretrizes do planejamento, da ordenação e controle do uso do solo a fim de se evitar a degradação da qualidade ambiental.

3.4 Princípio da participação: A participação das pessoas e das organizações não governamentais - ONGs, nos procedimentos de decisões administrativas e nas ações judiciais ambientais deve ser facilitada e encorajada, visando à conservação do meio ambiente.

A CF coloca no art. 225, caput, e inciso VI: "meio ambiente... bem de uso comum do povo... impondo-se ao Poder Público e à coletividade o dever de defendê-lo e preservá-lo." O Poder Público deve "promover a educação ambiental em todos os níveis de ensino e a conscientização pública para a preservação do meio ambiente."

A Declaração Rio/92 diz em seu art. 10: "O melhor modo de tratar as questões do meio ambiente é assegurando a participação de todos os cidadãos interessados, no nível pertinente"

O professor Paulo Affonso Leme Machado (2003, p. 84 e 86), coloca:

A participação na interposição de recursos administrativos é fundamental para que haja possibilidade de os interessados baterem à portas da própria Administração, para que ela reveja seus atos irregulares.

A Declaração do Rio de Janeiro/92 afirma que: 'Deve ser propiciado acessos efetivo a mecanismos judiciais e administrativos, inclusive no que diz respeito a compensação e reparação de danos.

A possibilidade de as pessoas e de as associações agirem perante o Poder Judiciário é um dos pilares do Direito Ambiental. Para que isso se tornasse realidade foi necessária a aceitação do conceito de que a defesa do meio ambiente envolve interesses difusos ou coletivos. 


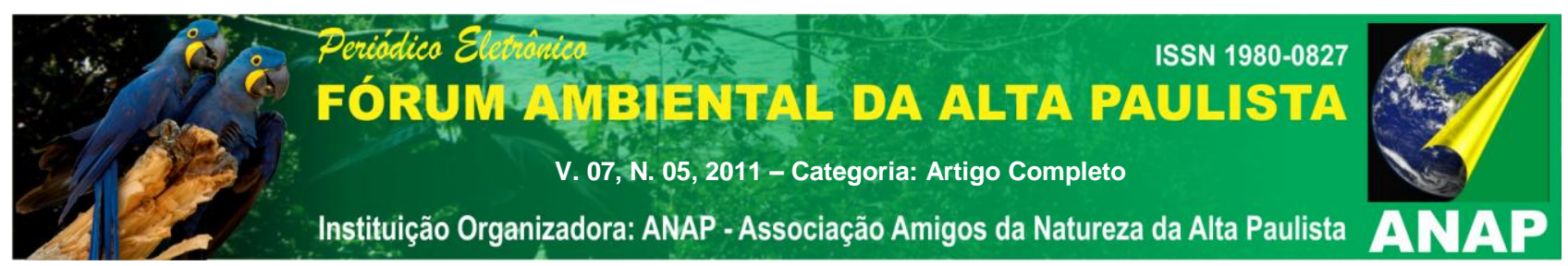

Importante destacar que no princípio da participação está inserido o direito a informação e a educação ambiental, que são mecanismos essenciais pra atingir a tutela do bem ambiental envolvido.

A Declaração de Estocolmo 1972 traz em sua redação o princípio da Educação:

Princípio 19 - "A educação em assuntos ambientais, para as gerações jovens bem como para os adultos, com ênfase especial aos menos favorecidos é essencial para ampliar as bases de uma opinião esclarecida e de uma conduta responsável por parte de indivíduos, empresas e comunidades, quanto à proteção e melhoria do meio ambiente em sua plena dimensão humana".

3.5 Princípio da ubiquidade: O objeto da proteção ao meio ambiente deve ser levado em consideração toda vez que uma política, atuação, legislação sobre qualquer tema, atividade ou obra, tiver que ser criada e desenvolvida.

Se refere à política publica que deve estar atenta aos cuidados com o meio ambiente ao elaborar alguma atividade pública ou privada.

3.6 Princípio do usuário-pagador e do poluidor-pagador: O uso dos recursos naturais pode ser gratuito como pode ser pago. O poluidor deve, em princípio, assumir o custo da poluição, tendo em vista o interesse público. Uma atividade econômica deve arcar com os dividendos da degradação ambiental.

Este princípio se refere aos sujeitos que degradarem, poluírem, maltratarem o meio ambiente, sujeitando-os ao pagamento pela conduta deplorável.

A Lei 6.938/81 diz, no art. 4ํㅡ, VII, que a Política Nacional do Meio Ambiente visará "à imposição, ao usuário, da contribuição pela utilização de recursos ambientais com fins econômicos" e "à imposição ao poluidor e ao predador" da obrigação de recuperar e/ou indenizar os danos causados". 


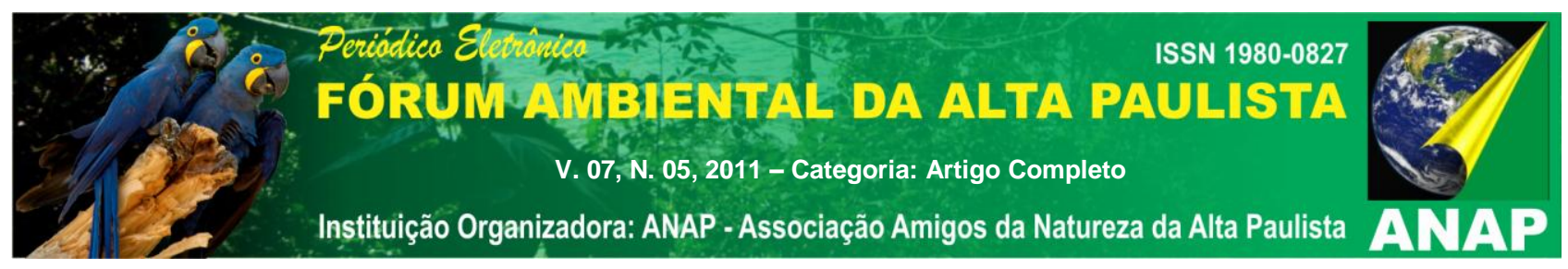

Estatuto da Cidade, art. 41, $\S 1^{0}$ : "No caso da realização de empreendimentos ou atividades enquadradas no inciso $\mathrm{V}$ do caput, os recursos técnicos e financeiros estarão inseridos entre as medidas de compensação adotadas."

A Declaração do Rio/92 destaca em seu princípio 16:

As autoridades nacionais devem procurar promover a internacionalização dos custos ambientais e o uso de instrumentos econômicos, tendo em vista a abordagem segundo a qual o poluidor deve, em princípio, arcar com o custo da poluição, com a devida atenção ao interesse público e sem provocar distorções no comércio e nos investimentos internacionais".

3.7 Princípio da obrigatoriedade da intervenção do Poder Público: Cabe ao Poder Público a tarefa de planificar, administrar e controlar a utilização dos recursos ambientais, com o fim de melhorar a qualidade do meio ambiente.

Está generalizada a idéia, na Declaração do Rio de Janeiro/92, principalmente no princípio 11 que diz: "Os Estados deverão promulgar leis eficazes sobre o meio ambiente".

Os Estados têm o papel de guardiães da vida, da liberdade, da saúde e do meio ambiente. Garantir a liberdade responsável: liberdade para empreender, liberdade para descobrir e aperfeiçoar tecnologias, liberdade para produzir e comercializar, sem arbitrariedades ou omissões dos Estados, liberdade que mantém a saúde dos seres humanos e a sanidade do meio ambiente. A liberdade que engrandece a humanidade e o meio ambiente exige um Estado de Direito, em que existam normas, estruturas, laborários, pesquisas e funcionários, independentes e capazes. (MACHADO, 2003, p. 92)

Atualmente verificamos a importância de um meio ambiente ecologicamente equilibrado devido às grandes modificações ocorridas especialmente no meio ambiente artificial (espaço urbano) com o movimento da chamada urbanização, que trouxe sérios problemas de estruturação e organização nesse meio urbano. Por isso destacamos esses princípios ambientais que tem por intuito proteger e melhorar o meio ambiente.

\section{CONSIDERAÇÕES FINAIS}




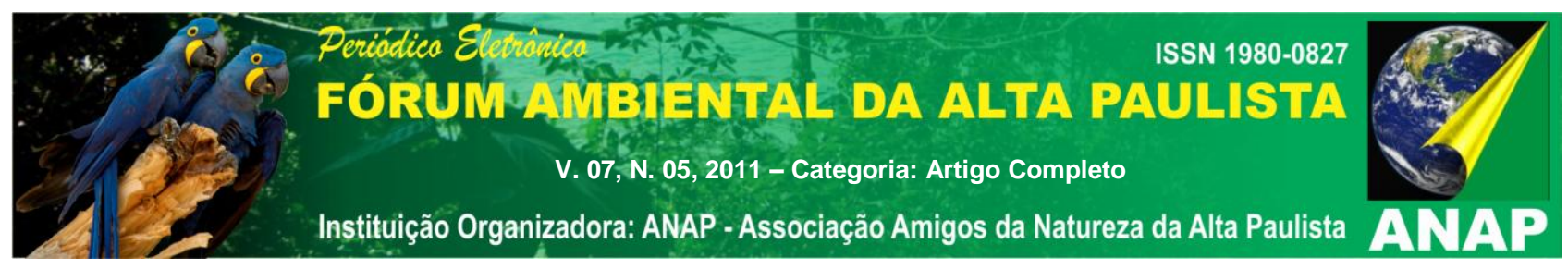

Vimos o cenário em que vivemos com os tipos de meio ambiente em que estamos inseridos. Destacamos os principais princípios ambientais e a importância deles para a sustentabilidade do meio ambiente. É evidente a necessidade mundial de olhar com carinho para o Meio Ambiente, pois a degradação ao longo dos anos foi muito grande, não só num determinado ponto do Globo terrestre, mas em todos os cantos, devido aos elementos da natureza agirem interligados, como clima, mar e solo.

Os princípios abordados fazem referencia aos vários setores do meio ambiente, nossos direitos e deveres, a inter relação e importância do Poter Público no tocante aos cuidados com o meio ambiente. $O$ desenvolvimento sustentável que é a base de todos esses princípios, juntamente com o princípio da sadia qualidade de vida em um meio ambiente equilibrado, é a máxima hoje no mundo. Em geral podemos resumir todos esses princípios e textos de referência sobre o meio ambiente nesses dois princípios basilares.

\section{REFERÊNCIAS BIBLIOGRÁFICAS}

BRASIL. Constituição (1988). Constituição da República Federativa do Brasil. Brasília, DF, senado. 1988.

FIORILLO, Celso Antonio Pacheco. Curso de direito ambiental brasileiro. 9. ed. rev., atual. e ampl. São Paulo: Saraiva. 2008.

MACHADO, Paulo Affonso Leme. Direito Ambiental Brasileiro, $11^{\text {a }}$ ed. rev. atual. e ampl. São Paulo: Editora Malheiros. 2003.

MILARÉ, Édis. Direito do Ambiente: doutrina, jurisprudência, glossário. 4 ed. São Paulo: Revista dos Tribunais, 2005

SILVA, José Afonso da. Direito ambiental constitucional. $3^{a}$ ed. São Paulo: Malheiros Editores. 2000. . Lei Federal ํㅜ 6.938, de 31.08.1981. Política Nacional do Meio Ambiente 